\title{
Enraizamento de estacas caulinares de ixora ${ }^{(1)}$
}

\author{
ALINE DE SOUZA SILVA ${ }^{(2)}$, NÍVEA PATRÍCIA RIBEIRO REGES(2), JÉSSICA KELLY DE MELO(2), MARCOS \\ PAULO DOS SANTOS ${ }^{(2)}$ e CLEITON MATEUS SOUSA(2)
}

\begin{abstract}
RESUMO
A ixora é uma espécie ornamental muito utilizada em paisagismo. Visando a maximizar a produção de mudas através da estaquia, avaliou-se a aplicação de ácido indolbultírico e a presença de folhas no enraizamento de estacas caulinares de Ixora coccinea $\mathrm{L}$. $\mathrm{O}$ experimento foi conduzido no delineamento de blocos ao acaso, em arranjo fatorial $3 \times 4$, sendo três tipos de estacas (sem folhas, com duas ou com quatro folhas) e quatro concentrações de ácido indolbultírico (0, 1000, 2000 e 4000 $\mathrm{mg} \mathrm{L}^{-1}$ ), com quatro repetições e 10 estacas em cada unidade experimental. Após 53 dias da implantação do experimento avaliou-se a sobrevivência(\%), enraizamento(\%), brotação(\%), formação de calos(\%), número, comprimento e biomassa das raízes formadas. A interação do tipo de estaca com as concentrações de auxina não foi significativa para nenhuma das variáveis analisadas. A sobrevivência das estacas não foi influenciada pelos tratamentos. Estacas com duas ou quatro folhas apresentaram enraizamento e comprimento de raízes superiores às estacas sem folhas. A aplicação de auxina não substitui a presença de folhas em estacas de ixora na propagação vegetativa. A ixora pode ser multiplicada através da estaquia, sem aplicação de auxina, desde que mantenha folhas nas estacas.
\end{abstract}

Palavras-chave: Ixora coccinea L., propagação vegetativa, auxina, floricultura, paisagismo.

\begin{abstract}
Rooting of stem cuttings of ixora

The ixora is ornamental plant widely used in landscaping. In order to maximize the propagation of cuts, we evaluated the concentrations of auxin (indolbutiric acid) and the presence of leaves on the rooting in cuts of Ixora coccinea L. The experiment was conducted in randomized block design, in factorial design $3 \times 4$, with three types of cuts (without leaf, with two or four leaves), four concentrations of indolbutiric acid $\left(0,1000,2000\right.$ and $\left.4000 \mathrm{mg} \mathrm{L}^{-1}\right)$, with four replications and 10 cuts in each experimental unit. After 53 days of implantation the experiment, evaluated the survival(\%), rooting( $\%)$, sprouting( $\%)$, formation of callus( $\%)$, number, length and biomass of roots formed. The interaction of the type of cuts with concentrations of auxin was not significant for any of the variables analyzed. The survival of cuttings was not influenced by the treatments. Cuts with two or four leaves presented rooting and length of roots above the cuttings without leaves. The application of auxin does not substitute the presence of leaf in cuts of ixora in vegetative propagation. The vegetative propagation by cut of ixora can be made without application of auxin, and the leaves must be maintained in the cuttings.
\end{abstract}

Keywords: Ixora coccinea L., vegetative propagation, auxin, floriculture, landscaping.

\section{INTRODUÇÃO}

A floricultura brasileira tornou-se uma atividade economicamente importante no agronegócio do país e tem apresentado notável desenvolvimento, ganhando qualidade, competitividade e ramificando se por todas as regiões do Brasil. O potencial de expansão da atividade está voltado tanto para o mercado interno como para exportação, com grandes oportunidades (BUAINAIN e BATALHA, 2007).

Em Goiás, ainda segundo esses autores, a floricultura comercial é pouco desenvolvida, devido à falta de um centro de comercialização no estado, o que dificulta o escoamento da produção, realizado na maioria dos casos por viveiristas, floriculturas e alguns supermercados, que comercializam essas flores tanto de forma unitária (flores de corte para pronto uso) quanto envasadas. Atualmente estima-se que existam cerca de 200 floriculturas no estado. A produção e comercialização concentram-se nos municípios de Goiânia, Goianira, Anápolis, Hidrolândia, Trindade e São Simão.

Estima-se que em 2013, o mercado de flores e plantas ornamentais no Brasil movimentou no valor global, cerca de $\mathrm{R} \$ 5,2$ bilhões, o que representou crescimento de $13 \%$ sobre os resultados do ano anterior (SCHOENMAKER, 2014). A floricultura tem se consolidado, também, com relevância do ponto de vista social, pois gera expressiva taxa de empregos os quais atraem pequenos produtores. Segundos dados do Instituto Brasileiro de Floricultura (IBRAFLOR, 2013) estima-se que o setor responda pela geração, na média nacional, de 15,2 empregos diretos por hectare, gerando um retorno de aproximadamente $\mathrm{R} \$ 20$ mil mensais por ponto de venda enquanto a mesma área de cana-de-açúcar abre 0,052 postos de trabalho e um retorno de apenas $\mathrm{R} \$ 3.893,72$ mensais aproximadamente (BINI, 2013; IBRAFLOR, 2013; UNICA, 2013).

\footnotetext{
(1) Recebido em 15/09/2014 e aceito para publicação em 22/06/2015

(2) Instituto Federal Goiano (IF Goiano), campus Ceres, Ceres-GO, Brasil. *Autor correspondente: sousacm@yahoo.com.br
} 
Das classes de plantas ornamentais, as espécies arbustivas são amplamente utilizadas pelas populações, dependendo da variedade, compondo bordaduras ou acompanhando cercas, muros, paredes e grades ou até mesmo individualmente, oferecendo uma diversidade de opções para uso no paisagismo apresentando formas, cores e volumes diferenciados (LIRA FILHO, 2002).

Dentre as espécies ornamentais arbustivas destacase a Ixora coccinea L. como a mais utilizada em projetos paisagísticos. Sua floração mantém-se ao longo do ano, diminuindo no inverno e, intensificando na primavera, o que resulta em jardins floridos e exuberantes (STENICO, 2013).

No que se refere ao seu manejo de produção e propagação vegetativa, constata-se uma grande carência de informações técnico-científicas visto que, os diferentes manejos preconizados na literatura não proporcionam melhorias significativas na produção de mudas.

A propagação vegetativa permite obter população uniforme, manter as características da planta-matriz (HARTMANN et al., 2002) e superar as limitações encontradas na propagação sexuada.

Segundo Dantas et al. (1999), é complicado estabelecer um tipo de material adequado para todas as espécies, uma vez que o enraizamento é influenciado por vários fatores, como condições de cultivo da planta matriz, nutrição, balanço hormonal, idade fisiológica e cronológica dos tecidos, etc. O tipo de estaca torna-se importante em espécies ou cultivares de difícil enraizamento e, nas de fácil enraizamento, obtém-se bons resultados mesmo que o material empregado não seja de boa qualidade.

Em estudo realizado por Sousa et al. (2014) foi observado efeito positivo da permanência de folhas nas estacas de maracujá doce sobre o percentual de enraizamento e sobrevivência das mesmas. A resposta da formação de raízes em estacas com folhas pode esta associada, possivelmente, com a síntese de fotoassimilados, substâncias nitrogenadas, hormônios, co-fatores e compostos fenólicos, ainda segundo a permanência das folhas nas estacas, Lima et al. (2007) relataram que estes compostos produzidos nas folhas, ao serem translocados para a base das estacas, acumulam-se na zona de regeneração e favorecem o enraizamento.

A aplicação de fitorreguladores influencia no enraizamento adventício, possibilitando a produção de mudas por estaquia de espécies consideradas de difícil enraizamento. Fitorreguladores à base de auxina como o ácido indolbutírico (AIB), ácido naftalenacético (ANA) e ácido indolacético (AIA) são os exemplos mais comuns de fitorreguladores empregados atualmente no processo de propagação de plantas por estacas (LIMA NETO et al., 2009).

Objetivou-se estabelecer estratégia para propagação vegetativa de Ixora coccinea L., comparando concentrações de auxina e tipo de estacas na formação de raízes adventícias em estacas caulinares de ixora.

\section{MATERIAL E MÉTODOS}

As estacas utilizadas forma preparadas a partir de ramos obtidos da poda de plantas matrizes de ixora (Ixora coccinea L.) cultivadas nas dependências do Instituto Federal Goiano - campus Ceres.

Os ramos coletados para obtenção das estacas estavam na fase vegetativa. A coleta de estacas foi realizada no dia 25 de fevereiro de 2013. Assim que coletadas, foram levadas ao viveiro do Setor de Fruticultura do Instituto Federal Goiano - campus Ceres e submetidas às etapas de preparação.

As estacas semi-lenhosas foram preparadas a partir das porções medianas e basais do ramo descartando-se as extremidades, de modo a conter, no mínimo, três gemas, com cerca de $15 \mathrm{~cm}$ de comprimento, com corte em bisel na base da estaca e um corte reto na extremidade apical das estacas. Foram preparadas estacas sem folhas, com duas folhas e com quatro folhas.

$\mathrm{O}$ experimento foi implantado no delineamento de blocos ao acaso, em arranjo fatorial $3 \times 4$, sendo três tipos de estacas (sem folhas, com duas ou com quatro folhas) e quatro concentrações de ácido indolbultírico (0, 1000, 2000 e $\left.4000 \mathrm{mg} \mathrm{L}^{-1}\right)$, com quatro repetições e 10 estacas em cada unidade experimental.

Após o preparo das estacas, o terço inferior da base foi imerso durante cinco segundos em solução de AIB (ácido indolbultírico), nas concentrações propostas, sendo, logo em seguida, inserido $1 / 3$ da base da estaca em canteiro de propagação, contendo areia como substrato, cobertura em forma de arco, com plástico transparente e 100 micras de espessura, com sistema de nebulização intermitente, com intervalos de 40 minutos a cada dois minutos de funcionamento, localizado a $0,60 \mathrm{~m}$ acima das estacas.

Aos 53 dias após a implantação do experimento, avaliou-se sobrevivência $(\%)$, enraizamento( $(\%)$, calos $(\%)$, brotação(\%) e perdas (mortas e ou podres), número de raízes, comprimento das raízes $(\mathrm{cm})$ averiguado com régua graduada de $30 \mathrm{~cm}$, biomassa fresca $(\mathrm{g})$ e seca das raízes(g) determinada através de balança analítica. Os dados obtidos foram submetidos à análise de variância (ANOVA) e as médias comparadas pelo teste Tukey, a 5\% de probabilidade de erro, utilizando o software Sisvar 5.1

\section{RESULTADOS E DISCUSSÕES}

A interação do tipo de estaca (com ou sem folhas) com as concentrações de auxina não foi significativa $(\mathrm{p}>$ $0,5)$ para nenhuma das variáveis analisadas. As tabelas 1 e 2 apresentam os resultados de enraizamento obtidos em função do tipo de estaca e concentrações de auxina. 
Tabela 1. Comportamento de estacas caulinares de Ixora coccinea L. em função da presença de folhas.

Table 1. Effects of the presence of leaves on the rooting of stem cuttings of Ixora coccinea L.

\begin{tabular}{|c|c|c|c|c|}
\hline \multirow{2}{*}{ Parâmetros } & \multicolumn{3}{|c|}{ Tipo de estaca* } & C.V. (\%) \\
\hline Sobrevivência (\%) & Sem folhas & Duas folhas & Quatro folhas & 1,45 \\
\hline Calo (\%) & $99,37 \mathrm{a}$ & $100,00 \mathrm{a}$ & $100,00 \mathrm{a}$ & 60,70 \\
\hline Brotação (\%) & $3,70 \mathrm{c}$ & $25,00 \mathrm{~b}$ & $43,75 \mathrm{a}$ & 14,99 \\
\hline Enraizamento (\%) & $98,12 \mathrm{a}$ & $83,75 \mathrm{~b}$ & $80,00 \mathrm{~b}$ & 6,27 \\
\hline Comp. raízes (cm) & $0,60 \mathrm{~b}$ & $96,80 \mathrm{a}$ & $98,10 \mathrm{a}$ & 34,95 \\
\hline Biomassa fresca (g) & $0,08 \mathrm{~b}$ & $3,77 \mathrm{a}$ & $4,20 \mathrm{a}$ & 51,56 \\
\hline Biomassa seca (g) & $0,00 \mathrm{~b}$ & $2,52 \mathrm{a}$ & $3,34 \mathrm{a}$ & 37,34 \\
\hline $\mathrm{N}^{\text {o }}$ raízes/estaca & $0,00 \mathrm{c}$ & $0,37 \mathrm{~b}$ & $0,54 \mathrm{a}$ & 34,08 \\
\hline
\end{tabular}

* Médias seguidas de mesma letra na linha não diferem entre si ao nível de $5 \%$.

Tabela 2. Enraizamento de estacas caulinares de Ixora coccinea L. em função de diferentes concentrações de ácido indolbultírico (AIB).

Table 2. Effects of concentrations of indolbultírico acid (IBA) on rooting of stem cuttings of Ixora coccinea L.

\begin{tabular}{|c|c|c|c|c|c|}
\hline \multirow{2}{*}{ Parâmetros } & \multicolumn{4}{|c|}{ AIB (mg.L $\left.{ }^{-1}\right)$ * } & \multirow{2}{*}{ C.V. $(\%)$} \\
\hline & $\mathbf{0}$ & 1000 & 2000 & 4000 & \\
\hline Sobrevivência (\%) & $100,00 \mathrm{a}$ & $100,00 \mathrm{a}$ & $100,00 \mathrm{a}$ & $99,16 \mathrm{a}$ & 1,45 \\
\hline Calo (\%) & $37,50 \mathrm{a}$ & $20,83 b$ & $15,83 b$ & $22,50 \mathrm{ab}$ & 60,70 \\
\hline Brotação (\%) & $92,50 \mathrm{a}$ & $90,83 a$ & $85,00 \mathrm{a}$ & $80,83 a$ & 14,99 \\
\hline Enraizamento (\%) & $64,17 \mathrm{a}$ & $67,50 \mathrm{a}$ & $64,17 \mathrm{a}$ & $65,00 \mathrm{a}$ & 6,27 \\
\hline Comp. raízes $(\mathrm{cm})$ & $2,83 \mathrm{a}$ & $2,45 \mathrm{a}$ & $2,91 \mathrm{a}$ & $2,53 \mathrm{a}$ & 34,95 \\
\hline Biomassa fresca (g) & $1,41 \mathrm{a}$ & $1,84 \mathrm{a}$ & $2,35 \mathrm{a}$ & $2,21 \mathrm{a}$ & 51,56 \\
\hline Biomassa seca (g) & $0,23 \mathrm{a}$ & $0,32 \mathrm{a}$ & $0,33 \mathrm{a}$ & $0,32 \mathrm{a}$ & 37,34 \\
\hline $\mathrm{N}^{\mathrm{o}}$ raízes/estaca & $17,66 b$ & $26,95 \mathrm{a}$ & $22,98 \mathrm{ab}$ & $29,02 \mathrm{a}$ & 34,08 \\
\hline
\end{tabular}

*Médias seguidas de mesma letra na linha não se diferenciam entre si.

A sobrevivência das estacas de ixora foi acima de $99 \%$, e não foi influenciada pelo tipo de estaca assim como pelas concentrações de auxina (Tabelas 1 e 2 ). Bastos et al. (2004) verificaram que as concentrações de AIB também não apresentaram efeito significativo na sobrevivência de estacas de caramboleira (Averrhoa carambola L.). Já Fochesato et al. (2006), observaram que o tipo de estaca influenciou na sobrevivência de estacas de louro (Laurus nobilis L.), enquanto as concentrações de AIB não apresentaram nenhuma influência.

Faria et al. (2007) descreveram que em portaenxerto de videira, a porcentagem de sobrevivência foi maior nas estacas lenhosas contendo folhas, sendo que o tratamento com AIB aumentou significativamente a mortalidade das estacas sem folhas.
A morte das estacas na maioria das vezes está associada com o esgotamento das reservas acumuladas nos tecidos. A presença de folhas nas estacas permite a produção de carboidratos assim como de complexos responsáveis pelo enraizamento, possibilitando a sobrevivência das estacas por um maior período de tempo (BORDIN et al., 2005), consequentemente, este maior período de sobrevivência possibilita a manifestação de respostas aos estímulos endógenos e exógenos das moléculas de auxinas .

No entanto, em estacas semi-lenhosas (caso da ixora) ou lenhosas, a presença de folhas não se torna fator limitante para a sobrevivência das estacas provavelmente pelo fato destas, apresentarem uma maior quantidade de substâncias de reserva (HARTMANN et al., 2002), evidenciando assim que fatores externos como umidade, 
temperatura e luminosidade seriam mais determinantes para a sobrevivência (FOCHESATO et al., 2006) do que a manutenção de folhas nas estacas, corroborando dessa forma os resultados obtidos neste estudo.

A presença de folhas reduziu a brotação das estacas (Tabela 1), enquanto as concentrações de AIB não influenciaram na brotação (Tabela 2). Pio et al. (2005) observaram que estacas de oliveira (Olea europaea L.) sem folhas apresentaram média de $75,71 \%$ de brotação, enquanto estacas com um par de folhas média de 32,91\% e estacas com dois pares de folhas $24,18 \%$.

A presença de folhas tende a reduzir a brotação de estacas conforme demonstrado na literatura e nos resultados obtidos neste trabalho. Esse processo possivelmente ocorre devido às folhas serem fonte de auxina, e com o transporte em direção à base da estaca, ocorre a inibição do desenvolvimento das gemas laterais.

A ausência de folhas nas estacas de ixora reduziu a formação de calos. Enquanto, apenas 3,7\% das estacas sem folhas formaram calo, observou-se calo em $25 \%$ das estacas com duas folhas e em $43,75 \%$ das estacas com quatro folhas (Tabela 1). As concentrações de 1000 e $2000 \mathrm{mg} \mathrm{L}^{-1}$ de AIB reduziram a formação de calo, sendo que na ausência de AIB, houve maior formação de calo (Tabela 2).

Em estacas de amoreira-preta não foi observado efeito significativo das concentrações utilizadas de AIB para a variável porcentagem de estacas calejadas (VILLA et al., 2003). Já Mayer et al. (2008) observaram $100 \%$ de estacas com calos para os tratamentos: 0,500 , 1000,1500 e $2000 \mathrm{mg} \mathrm{L}^{-1}$ de AIB e 56,67\% de estacas vivas enraizadas de caliandra (Calliandra tweedii), porém mesmo ocorrendo a formação de calos não foi identificada a formação de meristemóides nesses tecidos, visto que as raízes tiveram origem diretamente de células da região externa do floema junto ao periciclo ou da região interna do floema secundário próximo ao câmbio.

$\mathrm{O}$ enraizamento em estacas de ixora somente foi influenciado pelo tipo de estaca (tabela 1) e constatouse que a presença de folhas foi fundamental para o enraizamento. Enquanto as estacas sem folhas apresentaram média de enraizamento de apenas $0,6 \%$, as estacas com folhas apresentaram média acima de 96\%.

Sousa et al. (2014) verificaram que a presença de folhas foi essencial para a formação de raízes adventícias em estacas caulinares de maracujá-doce, corroborando com os resultados obtidos com estacas de Ixora. Em estacas semilenhosas de louro a associação da presença de quatro folhas com $2000 \mathrm{mg} \mathrm{L}^{-1}$ de AIB gerou a formação de raízes de maior comprimento e matéria fresca total (FOCHESATO et al., 2006).

$\mathrm{O}$ fato da existência de folhas ter favorecido o enraizamento em estacas de ixora neste estudo (Figura 1), pode estar associado com a produção de carboidratos assim como de moléculas com ação hormonal que ocorrem principalmente nas folhas, e podem ser translocadas e acumuladas na base das estacas, local que houve a formação das raízes adventícias, concordando com o pressuposto por Lima et al. (2007). Dessa forma, estacas com folhas podem enraizar mais rapidamente, entretanto, é necessário se atentar quanto a espécies de folhas grandes, pois podem apresentar desidratação excessiva das folhas.

As folhas de ixora são consideradas pequenas, fator que quando combinado com alta umidade relativa do ar presente em ambientes como canteiros de propagação cobertos e recebendo nebulização intermitente, pode ter contribuído para evitar a desidratação das estacas.

Mesmo em estacas contendo folhas não foi observado efeito da aplicação de AIB sobre o enraizamento. Lajús et al. (2007) verificaram que o uso do AIB aumentou, em todas as concentrações testadas em estacas de figueira, a porcentagem de enraizamento e a qualidade do sistema radicular formado. Já Pio et al. (2006) relataram que a aplicação de auxina em estacas de figueira torna-se inviável, uma vez que a diferença percentual de enraizamento obtida em relação a testemunha foi de apenas 7,92\%.

Verifica-se que a divergência nas respostas de enraizamento adventício observadas entre as espécies e condições de cultivo possivelmente associa-se a outros fatores envolvidos no processo, tais como a idade dos tecidos utilizados, reservas contidas, balanço hormonal nos tecidos, sensibilidade celular, presença de outras moléculas nos tecidos e condições nutricionais e fitossanitárias da planta matriz.

Gontijo et al. (2003) constataram efeito significativo da interação entre as concentrações de AIB e o tipo de estacas de aceroleira (número de pares de folhas na estaca) na porcentagem de enraizamento e no comprimento da raiz, sendo as maiores porcentagens de enraizamento (50\%) obtidas em estacas com quatro folhas e tratadas com $2.800 \mathrm{mg} \mathrm{L}^{-1}$ de AIB. Esses autores ressaltaram ainda, a importância da presença de folhas para o enraizamento de estacas de aceroleira, já que nas estacas sem folhas não ocorreu a formação de raízes.

A aplicação de auxina não influenciou no comprimento médio, na biomassa fresca e seca das raízes (Tabela 2). Já a presença de folhas exerceu influência direta sobre o comprimento das raízes, número de raízes por estaca, biomassa fresca e biomassa seca (Tabela 1), para todas essas variáveis a presença de folhas nas estacas possibilitou maiores resultados. Estacas com quatro folhas apresentaram maior número de raízes por estaca, o que consequentemente proporcionou maior biomassa seca (Tabela 1).

Carvalho et al. (2007) certificaram que em miniestacas de maracujazeiro amarelo a produção de massa seca de raízes foi estimulada pela presença da folha, elevando a massa produzida em 52,6\%, enquanto (BASTOS et al., 2009) não verificaram influência da aplicação de ácido indolbutírico na sobrevivência, formação de calos e número de raízes em estacas de caramboleira.

Faria et al. (2007) observaram que a aplicação de AIB a $2000 \mathrm{mg} \mathrm{L}^{-1}$ aumentou o comprimento, a massa fresca e seca das raízes de estacas com folhas de porta-enxerto de videira. Em estacas de figueira a auxina reduziu o comprimento das raízes (SOUSA et al., 2013). Já em estacas de Hibiscus rosa-sinensis L., o maior número de raízes foi encontrado nas maiores concentrações de AIB (PIZZATTO et al., 2011). 


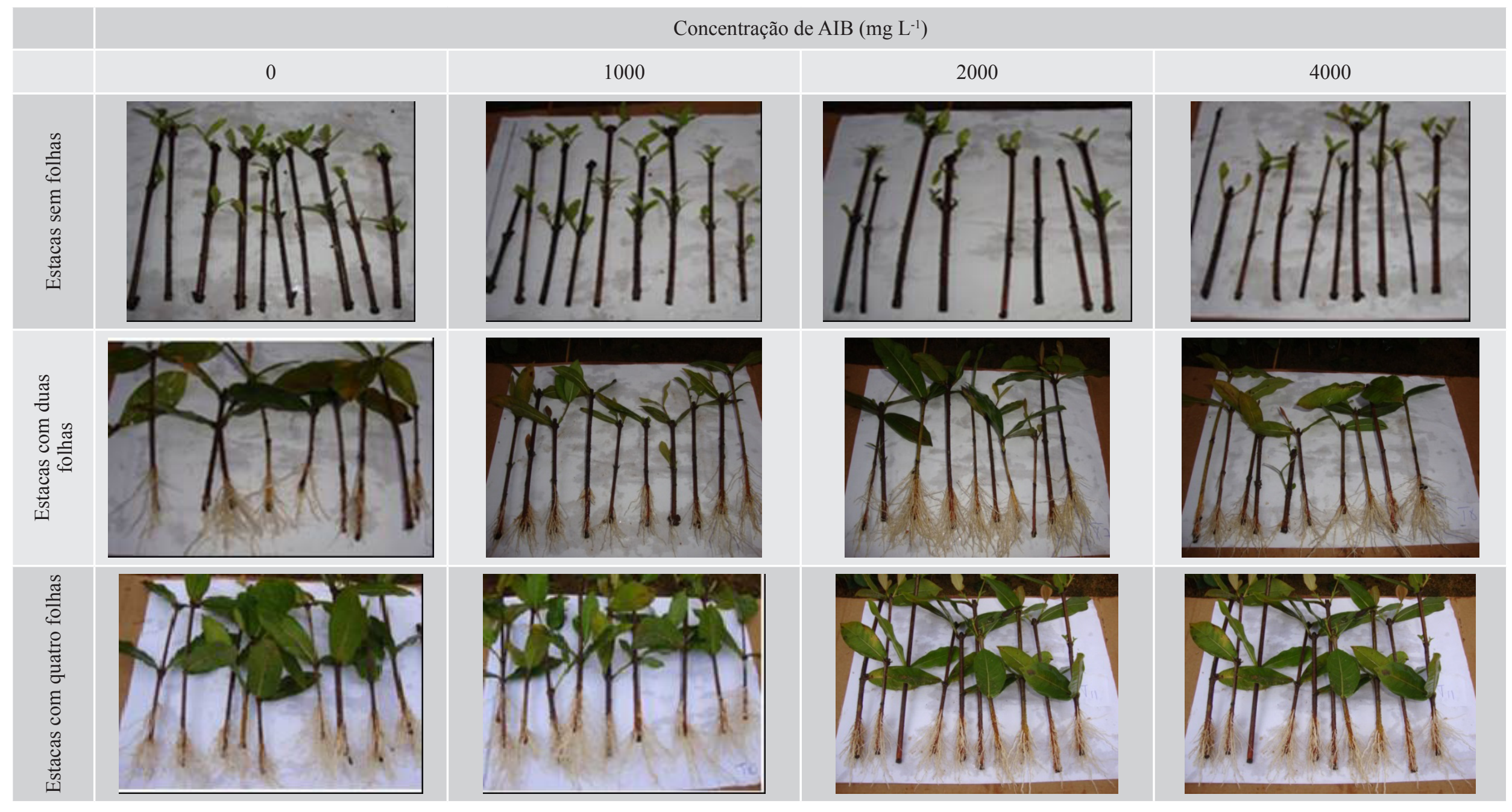

Figura 1. Enraizamento de estacas de ixora em função da aplicação de auxina e da presença de folhas. Figure 1. Response of rooting in cuts of the ixora in function application of auxin and the presence of leaves. 


\section{CONCLUSÕES}

O enraizamento de estacas caulinares de ixora somente foi influenciado pela presença de folhas.

A aplicação de ácido indolbutírico (AIB) não incrementou o enraizamento adventício de estacas lenhosas de Ixora coccinea L.

A propagação de ixora por estaquia pode ser realizada sem a aplicação de auxina, desde que se mantenha, no mínimo, um par de folhas nas estacas.

\section{REFERÊNCIAS}

BASTOS, D.C.; SCARPARE FILHO, J.A.; LIBARD, M.N.; PIO, R. Estiolamento, incisão na base da estaca e uso do ácido indolbutírico na propagação da caramboleira por estacas lenhosas. Ciência e Agrotecnologia, Lavras, v.33, n.1, p.313-318, 2009. DOI: <http://dx.doi.org/10.1590/ S1413-70542009000100043>

BINI, D.L.C. Preços Recebidos pelos Produtores de Canade-Açúcar no Estado de São Paulo, Safra 2012/13. Análises e Indicadores do Agronegócio. Instituto de Economia Agrícola, São Paulo, v.8, n.7, julho 2013. ISSN 1980-0711.

BUAINAIN, A.M.; BATALHA, M.O. (Coord.). Cadeias produtivas de flores e mel. Brasília: Instituto Interamericano de Cooperação para a Agricultura - IICA MAPA/SPA, Brasília, v.9, jan., 2007. Disponível em:<http:www.iica.org. $\mathrm{br} /$ DocsCadeiasProdutivas/Cadeia\%20Produtiva\% $\% 20 \mathrm{de} \% 20$ Flores\%20e\%20Mel.pdf $>$. Acesso em: 20 de setembro de 2013.

CARVALHO, R.I.N.; SILVA, I.D.; FAQUIM, R. Enraizamento de miniestacas herbáceas de maracujazeiro amarelo. Semina: Ciências Agrárias. Londrina, v.28, n.3, p.387-392, 2007. DOI: http://dx.doi.org/10.5433/16790359.2007v28n3p387

DANTAS, A.C.M.; DUTRA, L.F.; KERSTEN, E. Influência do etefon e do tipo de estaca no enraizamento de goiabeira (Psidium guajava L.). Revista Brasileira de Agrociência, Pelotas, v.5, n.1, p.19-21, 1999.

FARIA, A.P.; ROBERTO, S.R.; SATO, A.J.; RODRIGUES, E.B.; SILVA, J.V.; SACHS, P.J.D.; CAMOLESI, M.R.; UNEMOTO, L.K. Enraizamento de estacas semilenhosas do porta-enxerto de videira "IAC 572-Jales" tratadas com diferentes concentrações de ácido indolbutírico. Semina: Ciências Agrárias. Londrina, v.28, n.3, p.393-398, 2007. DOI: http://dx.doi.org/10.5433/1679-0359.2007v28n3p393

FOCHESATO, M.L.; MARTINS, F.T.; SOUZA, P.V.D.; SCHWARZ, S.F.; BARROS, I.B.I. Propagação de louro (Laurus nobilis L.) por estacas semilenhosas com diferentes quantidades de folhas e tratadas com ácido indolbutírico. Revista Brasileira de Plantas Medicinais. Botucatu, v.8, n.3, p.72-77, 2006.
GONTIJO, T.C.A.; RAMOS, J.D.; MENDONÇA, V.; PIO, R.; ARAÚJO NETO, S.E.; CORRÊA, F.L. O. Enraizamento de diferentes tipos de estacas de aceroleira utilizando ácido indolbutírico. Revista Brasileira de Fruticultura. Jaboticabal, v.25, n.2, p.290-292., 2003. DOI: http://dx.doi.org/10.1590/S0100-29452003000200027

HARTMANN, H.T.; KESTER, D.E.; DAVIES JR, F.T.; GENEVE, R.L. Plant propagation: principles and pratices. 7 ed. New Jersey: Prentice Hall, 2002.

INSTITUTO BRASILEIRO DE FLORICULTURA (IBRAFLOR). Números do setor: Mercado interno. Campinas, São Paulo, 2013. Disponível em: <http://www. ibraflor.com/ns_mer_interno.php $>$. Acesso em: 01 de Setembro de 2014.

LAJÚS, C.R.;SOBRAL, L.S.; BELOTTI, A.; SAVARIS, M.; LAMPERT, S.; SANTOS, S. R.F.; KUNST, T. Ácido Indolbutírico no enraizamento de estacas lenhosas de figueira (Ficus carica L.). Revista Brasileira de Biociências, Porto Alegre, v.5, supl.2, p.1107-1109, 2007.

LIMA，D.M.; ALCANTARA，G.B.; FOGAÇA， L.A.; QUOIRIN, M.; CUQUEL, F.L.; BIASI, L.A. Influência de estípulas foliáceas e do numero de folhas no enraizamento de estacas semilenhosas de maracujazeiro amarelo nativo. Acta Scientiarum Agronomy, Maringá, v.29, n.5, p.671676, 2007. Suplemento Especial. DOI: http://dx.doi. org/10.4025/actasciagron.v29i5.744

LIMA NETO, M.C.; RIBEIRO, J.S.; BEZERRA NETO, E. Enraizamento de estacas de bambu com o uso de auxinas. Revista Acadêmica Ciências Agrárias e Ambientais, Curitiba, v.7, n. 2, p.175-179, 2009.

LIRA FILHO, J.A. Paisagismo: elementos de composição e estética. Série Planejamento Paisagístico. Aprenda Fácil. Viçosa, v.2, p.194. $9^{\circ}$ Coleção. 2002.

MAYER, J.L.S.; CARDOSO, N.A.; CUQUEL, F.; BONA, C. Formação de raízes em estacas de duas espécies de calliandra (leguminosae - mimosoideae). Rodriguésia, Curitiba, v.59, n.3, p.487-495, 2008.

PIO, R.; ARAÚJO, J.P.C.; BASTOS, D.C.; ALVES, A.S.R.; ENTELMANN, F.A.; SCARPARE FILHO, J.A.; MOURÃO FILHO, F. A.A. Substratos no enraizamento de estacas herbáceas de figueira oriundas da desbrota. Ciência e Agrotecnologia, Lavras, v.29, n.3, p.604-609, 2005. DOI: http://dx.doi.org/10.1590/S1413-70542005000300014

PIO, R.; RAMOS, J.D.; CHALFUN, N.N.J.; CONTIJO, T.C.A.; MENDONÇA, V.;CARRIJO, E.P.; CHAGAS, E. Propagação de estacas apicais de figueira: diferentes ambientes, ácido indolbutírico e tipo de estaca. Ciência e 
Agrotecnologia. Lavras, v.30, n.5, p.1021-1026, 2006.

PIZZATTO, M.; WAGNER JR, A.; LUCKMANN, D.; PIROLA, K.; CASSOL, D.A.; MAZARO, S.M. Influência do uso de AIB, época de coleta e tamanho de estaca na propagação vegetativa de hibisco por estaquia. Revista Ceres, Viçosa, v.58, n.4, p.487-492, 2011. DOI: http:// dx.doi.org/10.1590/S0034-737X2011000400013

SCHOENMAKER, K. Agência Brasil: Floricultura brasileira faturou R\$ 5,2 bilhões no ano passado. 2014. Disponível em: <http://memoria.ebc.com.br/agenciabrasil/ noticia/2014-01-19/floricultura-brasileira-faturou-r-52bilhoes-no-ano-passado>. Acesso em 12 de Maio de 2015.

SOUSA, C.M.; BUSQUET, R.N.; VASCONCELLOS, M.A.S.; MIRANDA, R.M. Effects of auxin and misting on the rooting of herbaceous and hardwood cuttings from the fig tree. Revista Ciência Agronômica. Fortaleza, v.44, n.2, p.334-338, 2013. DOI: http://dx.doi.org/10.1590/S180666902013000200016

SOUSA, C.M; SANTOS, M.P; CARVALHO, B.M. Enraizamento de estacas de maracujazeiro-doce (Passiflora alata Curtis). Científica, Jaboticabal, v.42, n.1, p.68-73, 2014.
STENICO, A.R.P. Central de Abastecimento de Campinas (CEASA). 2013. Disponível em: <http:// www.ceas acampinas.com.br/novo/Dicas Ver. asp id $=255 \&$ page $=$ dica_da_semana $>$. Acesso em 20 de Novembro de 2013.

UNIÃO DA INDÚSTRIA DE CANA DE AÇÚCAR (UNICA). Avanço da mecanização incentiva adoção de tecnologias de última geração em SP. 2013. Disponível em: <http://www.unica. com.br/noticia/2981091792031019628/avancodamecanizacaoincentiva-adocao-de-tecnologias-deultima-geracao-em-sp/>. Acesso em 02 de Maio de 2014.

VILLAF.; PIO, R.; CHALFUN, N.N.J.; GONTIJO, T.C.A.; DUTRA, L.F. Propagação de amoreira-preta utilizando estacas lenhosas. Ciência e Agrotecnologia. Lavras, v.27, n.4, p.829-834, 2003. DOI: http://dx.doi.org/10.1590/ S1413-70542003000400013 
